\title{
УСТАВ СТАВРОПОЛЬСКОГО КРАЯ: ПРОБЛЕМНЫЕ ВОПРОСЫ И ПОИСК РЕШЕНИЯ
}

Устав Ставропольского края, являясь составной частью конституционного законодательства России, призван осуществлять правовое регулирование важнейших общественных отношений конституционного значения. Принятый в 1994 году краевой Устав претерпел существенные изменения в результате внесения множества поправок, продиктованных порой не реальными проблемами, а сиюминутными политическими интересами. Действующая редакция имеет бопьшое количество пробелов, не регулирует многие общественные отношения конституционного значения, в значительной части является формальным и декларативным документом. В итоге возникло реальное противоречие между фактическими общественными отношениями конституционного значения и положениями Устава, который призван осуществлять их правое регупирование, но не выполняет должным образом эту важнейшую конституционную функцию. Автором предложен концептуальный подход, получивший свое воплощение в Модельном проекте Устава Ставропопьского края, который размещен на новом информационном портале «Конституционно-правовой форум» для широкого обсуждения научно-экспертным сообществом. Концептуальный подход, положенный в основу Модепьного проекта, исходит из того, что краевой Устав должен обладать, по крайней мере, пятью ос- новными юридическими свойствами: учредительный характер; основополагающий характер; прямое действие; юридическое верховенство в краевой правовой системе; стабильность. В статье выделены проблемные вопросы, возникшие при уставном регулировании (в разрезе выделенных свойств Устава), обозначены допустимые пути решения и возможность законодательного воплощения в тексте нового Устава Ставропольского края.

Предложено понимание источника государственной впасти Ставропольского края, в качестве которого выступает народ Ставропольского края как составная часть многонационального народа Российской Федерации. Обоснована необходимость значительного массива уставных норм, имеющих непосредственное действие при минимуме числа отсылочных положений, рассмотрены основные из них в разрезе глав Модельного проекта Устава. Изложены доводы в пользу создания Уставного Суда Ставропопьского края, предпожены новые нормативные положения, обеспечивающие стабильность краевого Устава. Высказано предпожение об организации дискуссии о том, каким быть новому Уставу Ставропольского края.

Ключевые слова: Устав Ставропольского края, Модельный проект Устава Ставропопьского края, Конституционно-правовой форум.

\section{Cherepanov}

\section{CHARTER OF THE STAVROPOL KRAI: PROBLEM ISSUES AND SEARCH FOR SOLUTION}

The Charter of the Stavropol Krai, being an integral part of the constitutional legislation of Russia, is intended to carry out legal regulation of the most important public relations of constitutional significance. The Territorial Charter adopted in 1994 underwent significant changes as a result of the introduction of numerous amendments, dictated by sometimes not by real problems, but by short-term political interests. The current edition has a large number of gaps, does not regulate many public relations of constitutional significance, and is largely a formal and declarative document. As a result, a real contradiction between the actual social relations of constitutional significance and the provisions of the Charter has been arisen, though the Charter is called upon to exercise their rightful regulation, but has not properly performed this most important constitutional function. The author has proposed the conceptual approach that has been embodied in the Model Draft of the Charter of the Stavropol Krai, which has been posted on the new informational portal "Constitutional-Legal Forum" for broad discussion by the scientific and expert community. The conceptual approach underlying the Model Draft assumes that the Territorial Charter must have at least five basic legal properties: a constitutive character; fundamental character; direct action; legal supremacy in the regional legal system; stability. The article highlights the problematic issues that have arisen during the statutory regulation (in terms of the selected legal properties of the Charter), identifies permissible solutions and the possibility of their legislative implementation in the text of the new Charter of the Stavropol Krai.

The interpretation of the source of the government of the Stavropol Krai, which is the people of the Stavropol Kraias part of the multinational people of the Russian Federation, has been proposed. The necessity of a significant array of statutory rules that have direct effect with a minimum number of reference provisions has been substantiated; the main ones have been considered in the context of the chapters of the Model Draft of the Charter. The arguments in favor of the creation of the Charter Court of the Stavropol Kraihave been presented, new regulations to ensure the stability of the Charter of the Stavropol Kraihave been proposed. The proposal to organize a discussion on a new Charter of the Stavropol Kraihas been made.

Key words: Charter of the Stavropol Krai, Model Draft of the Charter of the Stavropol Krai, Constitutional-Legal Forum. 
12 декабря 1993 года многонациональный российский народ путем всенародного голосования принял новую Конституцию Российской Федерации (далее - Конституция) и этим актом суверенитета учредил новую федеративную государственность. Впервые многие регионы, являясь ранее лишь административными образованиями, получили возможность собственного законодательного регулирования общественных отношений в рамках конституционного разграничения предметов ведения между Российской Федерацией и ее субъектами.

На основе новой Конституции в Ставропольском крае, как и во всей стране, проводились важнейшие государственно-правовые преобразования. 27 марта 1994 года впервые был избран его законодательный (представительный) орган Государственная Дума Ставропольского края (далее также - Дума, краевая Дума), деятельность которой во многом определила особенности конституционного становления Ставропольского края как субъекта современной России

Перед депутатами краевой Думы первого созыва, в числе которых посчастливилось быть автору этих строк, было непаханое правовое поле, которое они засевали первыми краевыми законами. Рассматривая события тех лет с позиции сегодняшнего дня и пользуясь современной юридической терминологией, представляется возможным полагать, что основным приоритетом правовой политики впервые созданного краевого законодательного органа была конституционализация всей жизнедеятельности Ставропольского края. Хотя такого слова тогда никто не произносил, поскольку в юридическом лексиконе того времени подобного термина попросту не существовало.

Если под конституционализацией, как это считается сегодня, понимать процесс институциональной и нормативной модернизации государства и права под воздействием Конституции, при котором речь идет о заполнении актуально значимого для жизнедеятельности российского народа пространства конституционными идеями и институтами [3, с.16], то становится понятным, что такое глобальное целеполагание лежало в основе всей деятельности краевого законодателя. В этой связи важнейшим стало принятие Устава Ставропольского края (далее также - краевой Устав, Устав), который, являясь составной частью конституционного законодательства России и одновременно, правовой основой краевого законодательства, призван осуществлять конституционную функцию по правовому регулированию наиболее важных общественных отношений конституционного (уставного) значения. При надлежащей их регламентации Устав, закрепляя общественное и государственное устройство Ставропольского края, становится фундаментом всей его жизнедеятельности.

Принятый в 1994 году краевой Устав претерпел существенные изменения в результате внесения множества поправок, продиктованных порой не реальными проблемами, а сиюминутными по- литическими интересами. За истекший период действовало 38 различных редакций Устава, в которых происходило постепенное и неуклонное «выхолащивание» его текста. Действующая редакция имеет большое количество пробелов не регулирует многие общественные отношения конституционного значения, в значительной части является формальным и декларативным документом и в этой связи не соответствует своему гордому имени «Основной Закон Ставропольского края».

Устав, по своей конституционно-правовой сущности, призван быть не только юридическим, но и идеологическим документом, на основе которого формируется мировоззрение, осуществляется воспитание и обучение подрастающего поколения. Однако в связи с декларативностью и пробельностью действующей редакции эта важнейшая идеологическая функция не реализуется. Устав, как правило, не изучается в школах и вузах, не имеет массового издания и распространения среди населения. Поэтому многие жители Ставрополья не знакомы с положениями Основного Закона Ставропольского края, на территории которого они проживают.

В итоге возникло реальное противоречие между фактическими общественными отношениями конституционного значения и положениями Устава, который призван осуществлять их правое регулирование, но не выполняет должным образом эту важнейшую конституционную функцию. В процессе развертывания данного противоречия произошло накопление «критической массы», при которой, как обосновано отмечается в научной литературе, возникла необходимость в принятии нового Устава, не ограничиваясь точечными поправками действующей редакции [4, с.46].

В рамках настоящей статьи с учетом научных разработок в этой области $[1,2,4,7]$ предложен концептуальный подход, получивший свое воплощение в Модельном проекте Устава Ставропольского края, который размещен на новом информационном портале «Конституционно-правовой форум» для широкого обсуждения научно-экспертным сообществом.

Концептуальный подход, положенный в основу Модельного проекта Устава, исходит из того, что краевой Устав для своего юридического бытия в качестве Основного Закона Ставропольского края должен обладать, по крайней мере, пятью основными юридическими свойствами:

1) учредительный характер:

2) основополагающий характер;

3) прямое действие

4) юридическое верховенство в краевой правовой системе;

5) стабильность.

Рассмотрим кратко основные проблемные вопросы, возникшие при уставном регулировании (в разрезе выделенных юридических свойств Устава), обозначим допустимые пути решения и поговорим о возможности их законодательного воплощения в тексте нового Устава Ставропольского края. 
1. Учредительный характер Устава Ставропольского края. Учредительный характер Устава заключается в том, что им, в соответствии с Конституцией, определяется конституционно-правовой статус Ставропольского края, закрепляется его общественное и государственное устройство и устанавливается, то есть учреждается краевая система органов государственной власти.

Учредительный характер Устава предопределен особым субъектом правотворчества, от имени которого он принимается. В этой связи возникает вопрос об источнике и носителе учредительной власти, посредством которой определяется конституционно-правовой статус Ставропольского края и учреждается краевая система органов власти. Поскольку источником власти Российского государства в целом является весь российский народ, постольку источником государственной власти Ставропольского края представляется обоснованным считать народ Ставропольского края как составную часть всего многонационального российского народа ${ }^{1}$ При таком подходе народ Ставропольского края выступает как территориальный публичный коллектив, который, являясь источником своей власти, учреждает органы своей власти. В этой связи возникает необходимость определить перечень показателей, при наличии которых можно утверждать о принадлежности граждан к краевому публичному коллективу.

Очевидно, что сам факт нахождения российского гражданина на территории края еще не свидетельствует о его принадлежности к краевому публичному коллективу. На Кавказские Минеральные Воды ежегодно приезжают миллионы граждан для лечения и отдыха, но они не входят в состав народа Ставропольского края, который избирает Губернатора и депутатов краевой Думы

При рассмотрении краевого публичного коллектива как социально-территориальной общности проживающих на территории Ставропольского края российских граждан, объединенных устойчивыми производственными, политическими и духовно-нравственными связями и отношениями, резонно полагать, что включенность в такие общественные отношения, объединяющие людей в целостный социальный организм, как раз и может свидетельствовать об их принадлежности к краевому сообществу. Очевидно, что к членам такого сообщества следует относить только тех, которые законно находятся в Ставропольском крае, осуществляя регистрацию по месту

1 По-видимому, словосочетание «народ Ставропольского края» звучит несколько непривычно и странно Это связано с тем, что в общественном сознании понятие «народ» воспринимается, прежде всего, в этнографическом значении, как этническая общность. Как обоснованно отмечает Т. Я. Хабриева, «для целей этнографии народ - это население, имеющее свой особенный уклад жизни, традиции и обычаи, сохранившиеся уникальные черты психического склада, оригинальную культуру и т.Д., а для конституционного права - общность, являющаяся источником государственной власти» $[6$, с. 17$]$ жительства или временного пребывания на его территории. В отношении последней категории граждан возможно дополнительное требование в виде определенного срока проживания на Ставрополье - им может быть один год, по истечении которого приехавший в Ставропольский край и зарегистрированный на его территории по месту пребывания становится членом краевого публичного коллектива. С учетом сказанного источником государственной власти Ставропольского края, по нашему мнению, необходимо считать его народ как составную часть многонационального народа Российской Федерации, состоящий из жителей Ставропольского края, к которым относятся граждане Российской Федерации, постоянно или преимущественно проживающие на территории Ставропольского края.

В этой связи постоянно проживающими в Ставропольском крае следует признавать граждан, зарегистрированных по месту жительства на его территории. Прибывшие для временного проживания, считаются преимущественно проживающими и, соответственно, жителями Ставропольского края, по истечении одного года с момента регистрации по месту пребывания на территории Ставропольского края. Тогда правом избирать в краевые и местные органы власти, участвовать в краевом и местном референдуме должны обладать граждане, постоянно или преимущественно проживающие в Ставропольском крае, не ограниченные в активном избирательном праве федеральными законами.

Именно такие методологические, по своей сути, положения, вытекающие из учредительной роли Устава, закреплены в его Модельном проекте.

2. Основополагающий характер краевого Устава заключается в том, что его положениями регулируются наиболее важные общественные отношения, составляющие основы государственного и общественного устройства. Однако при этом должны закрепляться не декларативные положения, у которых отсутствует регулятивное воздействие на общественные отношения, а правовые нормы, имеющие прямое действие на территории Ставропольского края, что требует некоторого пояснения.

В теории конституционализма, как известно, различаются две формы прямого действия конституционных норм - непосредственное и опосредованное, в основе разграничения которых лежат различные уровни правового регулирования: конституционными нормами и нормами текущего законодательства [8, с. 130-137]. Применительно к Уставу как региональному конституционному акту это выглядит следующим образом.

Все уставные нормы, имеют прямое действие, регулируя определенные общественные отношения, наделяя их участников определенными правами и обязанностями, предусматривая ответственность за неисполнение возложенных обязанностей. Однако уставные нормы при их прямом действии могут реализовываться как не- 
посредственно, так и опосредовано - путем конкретизации в иных законодательных актах

Возьмем, к примеру, статью 24 Устава, некоторые нормы которой непосредственно регулируют общественные отношения, связанные с выборами краевых депутатов, и не могут быть изменены обычными законами:

- Дума Ставропольского края состоит из 50 депутатов, избираемых сроком на пять лет;

- краевым депутатом может быть избран российский гражданин, достигший 21 года, обладающий в соответствии с федеральным законом пассивным избирательным правом, не имеющий гражданства иностранного государства либо вида на жительство или иного документа, подтверждающего право на его постоянное проживание на территории другого государства.

Данные уставные нормы имеют прямое и непосредственное действие и не нуждаются в конкретизации другими законодательными актами. Однако в этой же статье имеется еще одна норма, согласно которой порядок выборов депутатов устанавливается краевым законом. Эта норма имеет прямое действие, но для регулирования общественных отношений, связанных с указанными выборами, требует своей конкретизации в отдельном законодательном акте, действует на эти общественные отношения посредством принятого на ее основе обычного, так называемого ординарного закона.

Поскольку на уставном уровне закрепляются наиболее важные правовые нормы конституционного значения, которые не могут быть изменены в упрощенном порядке путем принятия обычных законов, постольку возникает неизбежный вопрос о том, какие из них, имеющие непосредственное действие, подлежат закреплению именно в Уставе, а не в текущем краевом законодательстве.

Возьмем, к примеру, порядок выборов депутатов, закрепленный в упомянутом краевом законе, который перед очередными выборами нередко меняется действующей Думой, причем порой специально «под себя». По этому поводу известный российский юрист М. А. Федотов, еще, не будучи председателем Совета при Президенте Российской Федерации по развитию гражданского общества и правам человека, с большим сожалением отмечал (применительно к выборам федеральных депутатов), что для каждых конкретных выборов специально принимаются новые законы: «Итак, складывается впечатление, что законодатель воспринимает законы о выборах как акты с ограниченным сроком действия, создаваемые ad hoc (что означает «специально для этого случая», примечание мое - В. Ч.). Поэтому так, видимо, и надо было их называть: Закон о выборах такой-то Думы» [5, с. 173].

По нашему глубокому убеждению, в Уставе для его конституирования в качестве Основного Закона Ставропольского края, необходимо предусмотреть значительный массив правовых норм, имеющих непосредственное действие при минимуме отсылочных положений. Остановимся на основных из них в разрезе структурных составляющих нового Устава.

2.1. Глава 1 Модельного проекта закрепляет Основы общественного и государственного устройства Ставропольского края, под которыми понимается совокупность правовых норм, закрепляющих устои, важнейшие исходные начала, основные принципы, на которых построена вся жизнедеятельность государственного образования под названием Ставропольский край.

В Основах общественного и государственного устройства Ставропольского края, как составной части конституционно-правового института Основ конституционного строя Российской Федерации, осуществляется конкретизация конституционных принципов организации общественного и государственного устройства применительно к Ставропольскому краю. В их числе выделим федерализм, приоритет прав и свобод человека и гражданина, народовластие, единство и разделение государственной власти, правовое государство, которые имеют региональные особенности своего отражения в Модельном проекте Устава Ставропольского края.

2.1.1. Конституционный принцип федерализма получает конкретизацию в статье 1 данного проекта, которая, определяя конституционно-правовой статус Ставропольского края в федеративных отношениях, содержит ряд правовых норм, дополняющих действующую редакцию Устава:

- возможность договорного разграничения компетенции между федеральными и краевыми органами государственной власти;

- полнота краевой государственной власти вне пределов ведения Российской Федерации и ее полномочий по предметам совместного ведения;

- право опережающего правового регулирования по предметам совместного ведения Российской Федерации и ее субъектов;

- уточненный и расширенный перечень полномочий Ставропольского края по предметам его ведения.

2.1.2. Конституционный принцип приоритета прав и свобод человека и гражданина получает свою конкретизацию в статьях 2 и 8 Модельного проекта. Так, в статье 2, во-первых, закреплено, что каждому, находящемуся на территории Ставропольского края обеспечиваются и гарантируются все конституционные права и свободы. Во-вторых, определено, что для жителей края за счет средств его бюджета могут быть установлены дополнительные гарантии осуществления и защиты их прав и свобод

Особое внимание уделено правовой возможности ограничения прав и свобод законами Ставропольского края. С учетом правовых позиций Конституционного и Верховного Суда закреплены следующие положения:

- права и свободы человека и гражданина моаут быть ограничены законом Ставропольского края, но только в пределах, установленных Конституцией и федеральными законами, 
соразмерно и пропорционально конституционным целям, закрепленным частью 3 статьи 55 Конституции ${ }^{1}$;

- установление дополнительных мер социальной поддержки и социальной помощи за счет средств бюджета Ставропольского края осуществляется законами Ставропольского края на основе принципа поддержания доверия граждан к закону и действиям государства ${ }^{2}$.

Исключительно важной представляется новая статья 8 «Казачество». Поскольку Ставропольский край исторически формировался как российская территория, заселяемая казачеством, постольку представляется необходимым закрепить в Уставе исторически казачьего края следующие положения:

«Казачество - исторически сложившаяся социальная общность в составе многонационального народа Ставропольского края, имеющая самобытные традиции и культуру. Органы государственной власти Ставропольского края и органы местного самоуправления в целях восстановления исторической справедливости в отношении казачества осуществляют необходимые меры по реализации федерального законодательства о казачестве, принимают нормативные правовые акты по вопросам возрождения казачества и обеспечивают их выполнение».

2.1.3. Конституционный принцип народовластия получает конкретизацию в статье 3 Модельного проекта, которая содержит ряд правовых норм, дополняющих действующую редакцию Устава:

- конституирование народа Ставропольского края в качестве источника его государственной власти, экспликация данного понятия и определение субъектов активного избирательного права на территории Ставропольского края (подробное обоснование дано выше при рассмотрении учредительного характера Устава Ставропольского края в пункте 1 настоящей статьи);

- постулирование конституционно-правовой ответственности депутатов и выборных должностных лиц перед народом Ставропольского края с закреплением возможности их отзыва избирателями;

- создание условий для расширения непосредственного участия жителей Ставропольского края в выдвижении кандидатов на краевых и муниципальных выборах, решении важнейших вопросов

\footnotetext{
${ }^{1}$ Абз. 4 п. 5 мотивировочной части Постановления Конституционного Суда от 04.04.1996 № 9-П по делу о проверке конституционности ряда нормативных актов города Москвы и Московской области, Ставропольского края Воронежской области и города Воронежа, регламентирующих порядок регистрации граждан, прибывающих на постоянное жительство в названные регионы; Определение Верховного Суда от 17.10.2007 № 19-Г07-22.

2 Постановление Конституционного Суда от 24.05.2001 № 8-П по делу о проверке конституционности пункта 3 статьи 1 Закона Ставропольского края «О признании утратившими силу отдельных положений законодательных актов Ставропольского края» в связи с жалобой гражданки М. С. Колесниковой
}

государственного и муниципального управления (народная, в том числе законодательная инициатива, наказы избирателей, отзыв депутатов и выборных должностных лиц);

- закрепление обязанности органов краевой и муниципальной власти выносить важнейшие вопросы социально-экономического развития на публичное обсуждение с опубликованием его итогов для всеобщего сведения.

2.1.4. Конституционный принцип единства и разделения государственной власти получает конкретизацию в статье 4 Модельного проекта, которая содержит ряд норм, дополняющих действующую редакцию Устава:

- органы законодательной, исполнительной и судебной власти не только самостоятельны в пределах своих полномочий, но и взаимодействуют между собой, уравновешивая друа друга;

- судебную власть Ставропольского края осуществляют суды Ставропольского края, к которым относятся мировые судьи и Уставный Суд Ставропольского края (подробное обоснование необходимости создания Уставного Суда содержится ниже в пункте 3 настоящей статьи);

- в осуществлении краевой государственной власти участвуют государственные органы Ставропольского края, к которым относятся Избирательная комиссия и Контрольно-счетная палата Ставропольского края.

2.1.5. Конституционный принцип правового государства получает конкретизацию в статье 5 Модельного проекта, в которой наряду с нормами действующей редакции Устава:

- закреплено понятие «законодательство Ставропольского края» и раскрыто его содержание;

- определено, что краевой Устав, закрепляя общественное и государственное устройство Ставропольского края, осуществляет непосредственное и стабильное регулирование наиболее значимых общественных отношений, которое не может быть изменено иными краевыми законами;

- установлено, что не исполнение законодательства Ставропольского края влечет юридическую ответственность, предусмотренную федеральными законами и законами Ставропольского края.

2.2. Глава 2 Модельного проекта «Дума Ставропольского края", закрепляя основы статуса краевой Думы и краевых депутатов, организацию деятельности Думы и порядок принятия краевых законов, содержит ряд норм, дополняющих действующую редакцию Устава.

2.2.1. Избирательные системы, на основе которых избираются краевые депутаты. Эти положения в связи с основополагающим характером и прямым действием Устава относятся к вопросам конституционного значения и подлежат закреплению уставными нормами, которые не могут быть изменены путем принятия обычных законов. В настоящее время краевая Дума, состоящая из 50 депутатов, избирается с примене- 
нием мажоритарной и пропорциональной избирательных систем, на основе которых формируется по 50 \% депутатского корпуса. Каждая из них имеет свои достоинства и недостатки

Начнем с мажоритарной системы, основными достоинствами которой, как известно, являются учет мнения большинства и персонификация избранного депутата. Однако недостатки используемой разновидности относительного большинства перевешивают все ее достоинства, поскольку при этом не учитываются голоса, поданные за других кандидатов, что приводит к искажению народного волеизъявления, как это, к примеру, имело место:

-навыборахДумывторогосозыва(1997 год), когда за кандидата, победившего по Промышленному одномандатному избирательному округу № 10, проголосовали 15,07 \% избирателей, принявших участие в голосовании (при явке $38,36 \%$ ). Вряд ли итоги таких выборов можно считать представительными, поскольку избранного депутата не поддержало абсолютное большинство принявших участие в голосовании $(84,93 \%)$, а за него проголосовали лишь 5,7 \% от общего числа всех избирателей $(38,36 \% \times 15,07 \%=5,7 \%)$;

- на довыборах Думы третьего созыва по Ессентукскому одномандатному округу № 5 (2002 год), когда за победившего кандидата проголосовали 19,31 \% принявших участие в голосовании (при явке $36,25 \%$ ). Избранного депутата не поддержало абсолютное большинство принявших участие в голосовании $(80,69 \%)$, а за него проголосовали лишь около $7 \%$ от общего числа всех избирателей $(36,25 \%$ × 19,31\% = 6,99\%).

Перечень подобных примеров можно продолжить. Однако и так ясно, что для того, чтобы обеспечить представительность краевой Думы с учетом мнения различных групп населения используемая мажоритарная система относительного большинства по одномандатным округам не во всём подходит.

Рассматривая другие разновидности мажоритарной системы, отметим следующее. Система абсолютного больиинстеа, создавая возможность проведения второго тура, является многозатратной и вряд ли применима, поскольку влечет за собой значительные бюджетные расходы. В этой связи предпочтительной (при фрормировании соответствующей части депутатского корпуса) выглядит разновидность мажоритарной системы с использованием многомандатных избирательных округов, которая применяется, например, на выборах Думы города Пятигорска, когда две трети депутатского корпуса избирается по одиннадцати двухмандатным округам. Анализ выборов действующей городской Думы (2016 год) показывает, что за двух победивших кандидатов в двухмандатных округах проголосовало подавляющее число избирателей, принявших участие в выборах: от 67 до $91 \%$.

Рассмотрим теперь особенности применения пропорциональной системы при формировании второй половины депутатского корпуса. До- стоинством этой избирательной системы является то, что она позволяет избирать Думу, состав которой $\mathbf{6}$ идеальном варианте адекватно отражает политический плюрализм общества и представляет интересы различных групп населения. Однако эти достоинства проявляются лишь при наличии партий, в совокупности адекватно отражающих интересы различных социальных групп и социальных слоев. Поскольку существующие политические партии не отражают волю значительной части российского общества ${ }^{1}$, постольку это достоинство проявляется не в полной мере и в значительной части перевешивается недостатками пропорциональной системы, к числу которых в первую очередь, относятся:

- отчуждение народа от участия в выдви жении кандидатов, поскольку единственными субъектами выдвижения кандидатов на пропорциональных выборах оказываются политические партии, а жители Ставропольского края, составляющие в своей совокупности народ Ставропольского края, (на выборах, которые являются высшим непосредственным выражением его власти) лишены конституционной возможности непосредственного выражения своей воли путем выдвижения кандидатов;

- неперсонифицированность выборов которая заключается в том, что избиратель голосует не за конкретных людей, а за партийный список кандидатов, многих из которых он не знает и не в состоянии оценить их пригодность для депутатской деятельности;

- отказ избранных депутатов от мандатов, когда известные люди включаются в партийные списки, не для того, чтобы стать депутатами, а в целях привлечения голосов избирателей к данной партии. Они активно участвуют в агитационной деятельности, обходя тем самым запрет для лиц, замещающих государственные должности и должности государственной службы, участвовать в агитации. В случае избрания они отказываются от мандатов, уступая свое место следующему кандидату из того же партийного списка. При этом результаты выборов не соответствуют воле народа, поскольку граждане голосуют за одних кандидатов, а мандаты получают другие люди, нередко не известные избирателям. В данном случае имеет место злоупотребление пассивным избирательным правом, поскольку такие лица, действуют в противоречии с целевым назначением пассивного избирательного права: представлять избирателей и выражать волю народа в краевой Думе.

Поскольку устранение двух недостатков пропорциональных выборов (неперсонифицированность и отчуждение народа от выдвижения кандидатов) возможно лишь на федеральном уровне, то на краевом уровне необходимо:

1 Так, результаты исследования, проведенного Всероссийским центром изучения общественного мнения за неделю до выборов депутатов действующей Государственной Думы, показали, что 25 \%, т.е. 1/4 населения страны не разделяют взгляды ни одной из политических партий. 
- уменьшить применение пропорциональной системы на выборах краевых депутатов до определенного федеральным законодательством минимального уровня в $25 \%$ от общего состава краевой Думы, что при действующей численности в 50 депутатов составляет 13 человек;

- на выборах той части краевой Думы, которая формируется по мажоритарной системе, использовать ее многомандатную разновидность:

- установить, что депутатский мандат, от которого отказывается победивший кандидат, передается другому партийному списку.

В этой связи возникает вопрос о численности краевых депутатов, которая с учетом сказанного может быть увеличена до 52 человек, из которых 13 депутатов избирается по пропорциональной системе, а 39 депутатов - по тринадцати трехмандатным округам (один округ - 3 депутата) Именно такая избирательная модель закреплена в статье 11 Модельного проекта Устава, разработанного на основании изложенного здесь авторского подхода.

2.2.2. Концепция полусвободного депутатского мандата, закрепленная статьей 12 Модельного проекта, согласно которой депутат обязан выполнять предвыборную программу и наказы избирателей, поддерживать связь с избирателями, отчитываться о своей деятельности, выполнении предвыборной программы и наказов избирателей. За неисполнение и ненадлежащее исполнение своих обязанностей к депутату могут быть применены меры конституционно-правовой ответственности в виде досрочного прекращения полномочий по решению краевой Думы, а также путем отзыва избирателями.

2.2.3. Расширены полномочия Думы по участию в формировании краевого Правительства и контролю за его деятельностью (статья 15 Модельного проекта). Закреплено, что Дума дает согласие Губернатору на назначение первых заместителей председателя Правительства (как определено в действующей редакции Устава), а также руководителей краевых органов в сфере финансов, экономического развития, дорожного хозяйства и транспорта и вправе рассматривать вопрос о недоверии указанным лицам. Коррупционные дела последних лет подтверждают необходимость усиления парламентского контроля за деятельностью исполнительных органов власти.

2.2.4. Расширен состав субъектов права законодательной инициативы, в который включены жители Ставропольского края при осуществлении ими народной инициативы (статья 17 Модельного проекта - обоснование приведено выше в пункте 2.1.3 настоящей статьи).

2.3. Глава 3 Модельного проекта «Губернатор Ставропольского края. Правительство Ставропольского края», закрепляя основы статуса Губернатора, краевого Правительства и организации их деятельности, содержит ряд норм, дополняющих действующую редакцию Устава.

2.3.1. Концепция полусвободного губернаторского мандата (статья 21 Модельного про- екта - обоснование приведено выше в пункте 2.2.2 настоящей статьи). Наряду с полномочиями Губернатора закреплены его обязанности перед народом Ставропольского края, избравшим его на эту должность, за неисполнение которых он быть отозван своими избирателями. В этой связи сформулирован текст присяги, которую Губернатор приносит народу Ставропольского края при вступлении в должность (статья 20).

2.4. Глава 4 Модельного проекта «Государственные органы Ставропольского края", определяя положение Избирательной комиссии и Контрольно-счетной палаты в системе государственной власти Ставропольского края, закрепляет основы их правового статуса, который детально регламентируется отдельными краевыми законами, принимаемыми на основе уставных норм.

2.5. Глава 5 Модельного проекта «Местное самоуправление в Ставропольском крае», закрепляя основы организации местного самоуправления, содержит ряд норм, дополняющих действующую редакцию Устава. Во-первых, подчеркнуто, что органы местного самоуправления не входят в систему органов государственной власти Ставропольского края. Во-вторых, установлено, что наделение органов местного самоуправления государственными полномочиями Ставропольского края осуществляется краевыми законами по согласованию с органами местного самоуправления.

2.5. Глава 6 Модельного проекта «Изменение Устава Ставропольского края» коренным образом отличается от текста действующей редакции Устава. Детальное обоснование ее основных положений изложено ниже в пункте 4 настоящей статьи.

3. Юридическое верховенство Устава в краевой правовой системе закреплено в действующей редакции, однако правовые гарантии такого юридического верховенства отсутствуют в связи с отсутствием в Ставропольском крае Уставного Суда. Поскольку вопрос о несоответствии законодательных и иных нормативных актов, принимаемых краевыми и муниципальными органами власти Уставу Ставропольского края не подсуден федеральным судам и может рассматриваться только краевым Уставным Судом ${ }^{1}$, то положения Устава о его юридическом верховенстве, не обеспеченные судебным нормоконтролем, представляются декларативными, не работающими и мертвыми нормами. В отсутствии судебного нормоконтроля уставные положения не являются обязательными для текущего правотворчества, следовательно, и сам краевой Устав не может считаться Основным Законом Ставропольского края.

В целях преодоления этого недостатка уставного регулирования в статье 4 Модельного проекта осуществлено конституирование Уставного

${ }^{1}$ Абзац второй п. 6 мотивировочной части Постановления Конституционного Суда от 16.06.1998 № 19-П «О толковании отдельных положений статей 125, 126 и 127 Конституции Российской Федерации». 
Суда как самостоятельного и независимого судебного органа, который осуществляет судебную власть посредством конституционного судопроизводства

4. Стабильность Устава, претендующего на роль Основного Закона Ставропольского края, означает его длительное действие без внесения существенных изменений в уставный текст. Стабильность Устава, как имманентное свойство Основного Закона обусловлена тем, что его положения, закрепляя общественное и государственное устройство Ставропольского края, являются своеобразным фундаментом всего краевого государственного образования. Если из фундамента государственного образования постоянно вытаскивать и заменять базовые для его жизнедеятельности правовые блоки, то государственное здание вряд ли будет устойчивым в своем функционировании.

Конституционно-правовой анализ показывает, что в Ставропольском крае возникло реальное противоречие между необходимостью стабильности Основного Закона и практикой его произвольного изменения в силу тех или иных политических устремлений. В этой связи в целях укрепления стабильности Устава Ставропольского края, а, следовательно, всего краевого публичного образования и предотвращения возможности его произвольного изменения в Модельном проекте Устава сконструирована специальная Глава 6 «Изменение Устава Ставропольского края», в которой закреплен ряд новых базовых положений, которых нет в действующей редакции Устава. В Модельном проекте Устава Ставропольского края:

- установлены два отдельных правовых режима внесения изменений в текст Устава: поправки и пересмотр Устава;

- положения глав 2, 3, 4, 5 Устава могут быть изменены путем внесения соответствующих поправок в Устав Ставропольского края;

- положения главы 1 Устава, которая закрепляет Основы общественного и государственного устройства Ставропольского края, и положения главы 6 Устава, которая определяет порядок внесения изменений в Устав, не могут быть изменены путем внесения поправок; если возникла необходимость внесения изменений в эти главы, осуществляется пересмотр действующего Устава с принятием нового Устава Ставропольского края;

- для рассмотрения предложений о поправках и пересмотре Устава создается постоянно действующая Уставная комиссия;

- предложения о поправках к Уставу, получившие одобрение Уставной комиссии, за исключением случаев приведения положений Устава в соответствие с Конституцией и федеральными законами, подлежат официальному опубликованию с проведением по ним публичных слушаний;

- поправки принимаются, если за них проголосовало не менее трех четвертей, а при приведении положений Устава в соответствие с Конституцией и федеральными законами - двух третей установленного числа депутатов;

- при необходимости внесения изменений в главы 1 и 6 Устава осуществляется пересмотр Устава с подготовкой новой редакции. Этот законопроект публикуется для всеобщего сведения и выносится на публичное обсуждение, с учетом результатов которого рассматривается в Думе Ставропольского края и может быть принят, если за него проголосовало не менее трех четвертей установленного числа краевых депутатов

- краевой закон о принятии нового Устава Ставропольского края вступает в силу по истечении 30 дней со дня его официального опубликования

Завершая разговор об Уставе Ставропольском крае, следует отметить, что изложенный здесь концептуальный подход не рассматривается как истина в последней инстанции. В научно-экспертном сообществе у различных его представителей возможно иное уставное правопонимание, что естественно и обосновано в условиях идейного многообразия научной и политической мысли. В настоящей статье сделана попытка обозначить лишь некоторые проблемы уставного регулирования и пригласить коллег к обсуждению вопроса о том, каким быть Уставу Ставропольского края. Необходимость в такой дискуссии, как представляется, назрела давно.

\section{Литература}

1. Гошуляк В. В. Теоретико-правовые проблемы конституционного и уставного законодательства субъектов Российской Федерации. М.: Янус-К, 2000. $334 \mathrm{c}$

2. Конституционное право субъектов Российской Федерации / отв. ред. В. А. Кряжов. М.: ООО «Городец-издат», 2002. $864 \mathrm{c}$.

3. Крусс В. И. Конституционализация права: основы теории: монография. М.: ЮрНорма, 2017. 176 с

4. Михалева Н. А. Конституции и уставы субъектов Российской Федерации (сравнительно-правовое исследование) М.: Юркомпани, 2010. 336 c.

5. Федотов М. А. Для защиты свободных выборов необходима защита свободы средств массовой информации // Российские выборы в контексте международных избирательных стандартов: Материалы международной конференции. М.: Аспект-пресс, 2006. С.172-175.

6. Хабриева Т. Я. Современные проблемы самоопределения этносов: сравнительно-правовое исследование. М. Институт зак-ва и сравнит. правовед. при Правительстве РФ , 2010. 288 с.

7. Цалиев А. М. Органы власти и законодательство субъектов Российской Федерации: состояние и проблемы совершенствования. М.: Формула права, 2007. 191 с.

8. Эбзеев Б. С. Введение в Конституцию России: монография. М.: Инфра М, 2015. 560 с 


\section{References}

1. Goshulyak V. V. Teoretiko-pravovye problemy konstitutsionnogo i ustavnogo zakonodatel'stva subsektov Rossiyskoy Federatsii (Theoretical and legal problems of the constitutional and constitutional legislation of the constituent entities of the Russian Federation). Moscow: Yanus-K publ., 2000. 334 p. (In Russian).

2. Konstitutsionnoe pravo sub») ektov Rossiyskoy Federatsii (Constitutional law of the constituent entities of the Russian Federation) / ed be V. A. Kryazhov. Moscow: Gorodets-izdat publ., 2002. 864 p. (In Russian)

3. Kruss V. I. Konstitutsionalizatsiya prava: osnovy teorii (The constitutionalization of law: the foundations of theory): monografiya. Moscow: YurNorma publ., 2017.176 p. (In Russian).

4. Mikhaleva N. A. Konstitutsii i ustavy sub) ektov Rossiyskoy Federatsii (sravnitel'no-pravovoe issledovanie) (Constitutions and charters of constituent entities of the Russian Federation (comparative legal study). Moscow: Yurkompani publ., 2010. 336 p. (In Russian).

5. Fedotov M. A. Dlya zashchity svobodnykh vyborov neobkhodima zashchita svobody sredstv massovoy informatsii (Protecting free elections requires protecting media freedom) // Rossiyskie vybory v kontekste mezhdunarodnykh izbiratel'nykh standartov: Materialy mezhdunarodnoy konferentsii. Moscow: Aspekt-press publ., 2006. P. 172-175. (In Russian).

6. Khabrieva T. Ya. Sovremennye problemy samoopredeleniya etnosov: sravnitel'no-pravovoe issledovanie (Modern problems of self-determination of ethnic groups: a comparative legal study). Moscow: Institute Law and Comparative Law Study Under the Government of the Russian Federation publ., 2010. 288 p. (In Russian).

7. TsalievA. M. Organy vlasti izakonodatel'stvo sub»ektov Rossiyskoy Federatsii: sostoyanie i problemy sovershenstvovaniya (Authorities and legislation of the constituent entities of the Russian Federation: state and problems of improvement). Moscow: Formula prava publ., 2007. 191 p. (In Russian).

8. Ebzeev B. S. Vvedenie v Konstitutsiyu Rossii (Introduction to the Constitution of Russia): monografiya. Moscow: Infra M publ., 2015. 560 p. (In Russian).

\section{Сведения об авторе}

Черепанов Виктор Алексеевич - доктор юридических наук, профессор кафедры государственного и муниципального управления и права Ставропольского государственного аграрного университета, заслуженный юрист Российской Федерации (Ставрополь) / sigma45@yandex.ru

\section{Information about the author}

Cherepanov Victor - Doctor of Law, Professor, Chair of State and Municipal Management and Law, Stavropol State Agrarian University, Honored Lawyer of the Russian Federation (Stavropol) / sigma45@ yandex.ru 